\title{
A Diagrammatic Approach to Understanding Complex Eco- Social Interactions in Kathmandu, Nepal
}

\author{
$\underline{\text { R. Cynthia Neudoerffer }}^{1}, \underline{\text { David Waltner-Toews }}^{1}$, James J. Kay ${ }^{2}$, D. D. Joshi ${ }^{3}$, and Mukta S. Tamang ${ }^{4}$
}

\begin{abstract}
As part of developing an international network of community-based ecosystem approaches to health, a project was undertaken in a densely populated and socio-economically diverse area of Kathmandu, Nepal. Drawing on hundreds of pages of narrative reports based on surveys, interviews, secondary data, and focus groups by trained Nepalese facilitators, the authors created systemic depictions of relationships between multiple stakeholder groups, ecosystem health, and human health. These were then combined to examine interactions among stakeholders, activities, concerns, perceived needs, and resource states (ecosystem health indicators). These qualitative models have provided useful heuristics for both community members and research scholars to understand the eco-social systems in which they live; many of the strategies developed by the communities and researchers to improve health intuitively drew on this systemic understanding. The diagrams enabled researchers and community participants to explicitly examine relationships and conflicts related to health and environmental issues in their community.
\end{abstract}

Key Words: complex systems theory; ecosystem approaches; human health; Kathmandu; Nepal; socialecological systems.

\section{INTRODUCTION}

Since about the mid-1990s, international development researchers have sought innovative and effective ways to address the links between health, development, and environmental change. While conventional epidemiological studies and integrated community development projects had gathered an impressive amount of information, and achieved some successes in preventing specific diseases, rapid social and ecological changes threatened to put many health achievements at risk. In this context, a variety of new conceptual models for understanding complex changes in social and ecological systems as well as innovations in research methods were proposed, ranging from ecosystem health and sustainable livelihoods to resilience and ecological integrity. The theoretical basis for and practical implementation of these various approaches have been summarized in several important volumes (Berkes and Folke 1998, Rapport et al. 1998, Kay et al. 1999, Helmore and Singh 2001, Gunderson and Holling 2002, Berkes et al. 2003, Waltner-Toews 2004).

One of the important cross-cutting themes in these various studies was the recognition of the intimate interconnection between social and ecological systems and the challenge to traditional approaches which attempt to study one or the other in isolation, particularly in relation to questions of environmental change. Social systems deal with governance, as in property rights and access to resources, and different systems of knowledge pertinent to the dynamics of environment and resource use, and worldviews and ethics concerning human-nature relationships. Ecological systems (or ecosystems) refer to selfregulating communities of organisms interacting with one another and with their environment (Berkes et al. 2003). Research approaches such as ecosystem health, sustainable livelihoods, resilience, and ecological integrity emphasize the integrated concept of humans-in-nature (Berkes and Folke 1998), meaning that humans are not seen as separate from their environment, but rather actively impacting upon and being influenced by it. In this perspective, the delineation between social and 
ecological systems is understood to be arbitrary and artificial. Some authors use the term socialecological system to emphasize this integrated concept (Berkes and Folke 1998, Gunderson and Holling 2002); we choose to use the term eco-social system (Waltner-Toews et al. 2003) to represent our understanding of the intimate links between the ecological and the social. Describing an eco-social system involves both a scientific description of the ecosystem and the creation of an "issues framework" (which things are deemed important, either positively or negatively, by the people who live there), based on an understanding of the culture and values of the people who live in the system (Kay et al. 1999).

In practical terms, in attempting to study eco-social systems what many of these new approaches sought were ways to integrate not only ecological and health variables but also stakeholders and decisionmakers into the research process itself. Some systems theorists had already posited that complex eco-social systems could only be characterized using multiple perspectives (Casti 1994, Roe 1998, Kay et al. 1999). Bringing multiple stakeholders into a collaborative research project from the beginning transformed this multiple-perspective theoretical principle into a very practical problem.

In 1998, the International Development Research Center (IDRC) in Ottawa, Canada, developed an innovative program, which explored several possibilities for integrating ecosystems and health research and development (LeBel 2003). The Nepal Urban Ecosystem Health Project (UEHP), part of IDRC's emerging program on Ecosystem Approaches to Health, was one of three in a network of IDRC-funded EcoHealth projects in which we were involved (the other two being in Kenya and Peru) whose underlying purpose was to develop a robust methodology for doing research into sustainability and health (Gitau et al. 1998, Murray et al. 2002, Waltner-Toews et al. 2003).

These EcoHealth projects strove to develop an ecosystem approach to health. Health is broadly defined by the World Health Organization (WHO) as "a complete state of physical, mental and social well-being and not merely the absence of disease or infirmity" (WHO Constitution 1948) and, "the extent to which an individual or group is able to, on the one hand, realize aspirations and satisfy need; and, on the other hand, change or cope with the environment". It is not an "objective for living" but "a resource for everyday life" (WHO, Alma Alta Declaration 1978). In 1986, the Ottawa Charter for Health Promotion added that "the fundamental conditions and resource for health are peace, shelter, education, food, income, a stable ecosystem, sustainable resources, social justice and equity" (WHO 1986). Health is about much more than 'not being sick', rather it is rooted in the ability and power to set and accomplish goals (Neilsen 1999). In this sense, health is always context specific and negotiated and rooted in a particular history and culture.

The fundamental concept of health, as defined in 1948 by the WHO, has remarkably withstood more than 50 years of academic debate. What has evolved over the last half century, as reflected in the various additional Declarations and Charters, is our understanding and approach to realizing health. Until the last decade of the twentieth century health was largely approached from the perspective of disease and the specialized application of medical science, often centered on diagnosis and prescription in a clinical setting (Peden 2002). This approach has been very successful at drastically reducing the instance of infectious diseases in the twentieth century in industrialized countries, and to a lesser extent in developing countries. However, despite notable progress, the approach isolated people from their physical environment and infectious disease still remains a leading cause of death in many parts of the developing world (PriceSmith 2002). A series of factors, such as growing resistance of disease vectors and pathogenic organisms to pesticides and antibiotic drugs, climate change, poverty, and environmental degradation have undermined much progress in the twentieth century (Lee 2001, Watson and McMichael 2001, LeBel 2003).

The traditional, clinical view of health focuses on a certain disease outcome as the result of a linear chain of events (e.g., water pollution from untreated sewage leads to diarrhea in the children who drink the water). But this linear approach misses much of the picture that can only be captured by considering the interaction of various feedback loops: certain types of economic activity while generating pollution are also important sources of livelihoods that generate income to improve nutrition and pay for improvements in public health infrastructure. The diarrhea afflicting people who drink the water also undermines their ability to work, resulting in lost wages and money for education and other 
productive activities. This feedback loop may be complicated by the fact that it is men who often earn the money, while the women and children suffer the major negative health consequences. Resolving this health problem requires untangling a series of interrelated disease, education, nutrition, livelihood, and gender issues, and requires that researchers go beyond traditional health sector concerns to consider the ecological and socio-economic context (Waltner-Toews and Kay 2002).

Recognition of the limitations of the clinical health model and the need for balance with preventative concepts from public health care have led to a broader view of human health, "one that goes beyond the biology and chemistry of people and medication, to take account of the human living conditions and ecosystems that influence human health" (Peden 2002:5).

Mirroring this change in thinking in the health field, the need for an ecosystem approach to study complex ecological and eco-social issues has also emerged and influenced many, including environmentalists, urban planners, agronomists, biologists, and sociologists (LeBel 2003). WaltnerToews and Kay (2005) provide a recent review of the evolution of ecosystem approaches. The first clear articulation of the concept in North America came from Allen et al. (1993) in their seminal work "The Ecosystem Approach". Since that time innumerable works have sought to elucidate the concept (Kay et al. 1999) and the concept has received widespread acceptance (e.g., Convention on Biological Diversity, the Millennium Ecosystem Assessment, and the U.S. Fish and Wildlife Service, to name only three) (CBD 2005, MEA 2005, US FWS 2005).

These concomitant changes in thinking in heath and environmental sciences contributed to the emergence of the field of ecosystem health. Ecosystem health is a broad umbrella term for an emerging discipline that bridges the natural, social, and health sciences, and seeks to provide environment and health management and policy professionals with a theoretical framework and methods, or practical tools, to improve society's ability to sustain earth's life-support systems (Wilcox 2001). Ecosystem health can be variously described as a metaphor, a developing body of theory or a paradigm, an applied science, and an emerging area of professional practice; thus there is no one agreed upon definition. Gaudet et al.
(1997:3) suggest that ecosystem health, "merges the socioeconomic with the traditional ecological/ environmental values in a way that recognizes and incorporates not only the biological integrity of ecosystems into decision making but also integrates humans, including their values, beliefs, and wellbeing, as part of a 'healthy' ecosystem". Other possible definitions are suggested by Costanza (1992) and Rapport (1995), and reviewed by Mageau et al. (1995) and Callicott (1995). Wilcox (2001) suggests that there are three main areas of focus within the field of ecosystem health. The first variant of the approach seeks to apply notions and metrics of health to develop ecological assessments, monitoring, audits, and indicators to determine the 'health of ecosystems'. Two examples of this type of approach are given by Yassi et al. (1999) and Spiegel et al.'s (2001) work to develop indicators for an urban ecosystem in Centro Habana, Cuba, and Aguilar's (1999) work to develop holistic ecosystem health indicators in Costa Rica.

In the second variant, human health is viewed from an ecological or ecosystem perspective. Hancock (1990) and VanLeeuwen et al. (1999) have both sought to reformulate models of health to bring the advances of ecosystem thinking to bear on the understanding of human health, that is, seeing humans as central elements, subsystems, or components nested hierarchically within a larger, complex eco-social system. McMichael and Kovats (2000) suggest several possible frameworks for integrating research into global environmental change and human health. This second approach is sometimes referred to as an 'ecosystem approach to human health' or EcoHealth.

The third variant, according to Wilcox (2001), represents the apogee of integrative concepts and methods relating both to ecosystems and human health and calls for the integration of public health, integrated resources management and ecosystem management in a community-based participatory action process. Gaudet et al. (1997) suggested an early possible framework and Parkes and Panelli (2001) have articulated and tested a comprehensive Community-Oriented Participatory Action Research (COPAR) approach.

All three of these approaches to 'ecosystem health' are equally valid and the emphasis depends on the research interests and questions being asked. Our particular interest in the UEHP has been to combine the latter two perspectives and develop an 
integrative and participatory ecosystem approach to health (EcoHealth).

\section{HISTORICAL BACKGROUND AND STATEMENT OF THE PROBLEM}

The UEHP grew out of earlier epidemiological studies in two urban wards (Wards 19 and 20) of Kathmandu (phase one). These studies, started in 1992, investigated cystic echinoccocosis, a parasitic zoonoses transmitted between dogs and other species, including people. This earlier work, focused on environmental and animal-related determinants of human health outcomes, resulted in the acquisition of a great deal of information, which was tabulated, statistically modeled, published, and used as the basis for public health messages. Despite using a variety of public health communication strategies, including publications, videos, television, radio, neighborhood clinics, and so on, we saw no substantive changes in the degraded physical state of the communities themselves (Baronet et al. 1994, Waltner-Toews et al. 2005). Animals were slaughtered along the mucky banks of the Bishnumati River, amid groups of water buffaloes awaiting slaughter, piles of stomach contents and feces from water buffaloes, discarded animal body parts, foraging pigs and dogs, temporary squatter huts, and playing children; women and children got their drinking water from standing pipes in the midst of all this bedlam. Piles of animal parts, human and animal feces, plastic bags, paper, vegetable waste from street vendors, and household wastes of various sorts could be found throughout the neighborhoods. Figures 1 and 2 are typical scenes from that time.

Despite the apparent intransigence of the problems in Kathmandu, the 1990s provided some unprecedented opportunities for change; the prodemocracy movement in Nepal, part of a larger and slower scale "creative destruction" movement against authoritarian regimes worldwide, engaged citizens actively in a variety of political processes, and succeeded in establishing a somewhat fragile multi-party democratic state (Holling 1986, Waltner-Toews et al. 2005). The timing was right for a shift from conventional scientific approaches to a more integrated, participatory strategy.
In 1998, initiated and led by the National Zoonoses and Food Hygiene Research Center (NZFHRC) and Social Action for Grassroots Unity and Networking (SAGUN), and collaborating with the University of Guelph, the new UEHP was designed as a Participatory Action Research (PAR) project on Urban Ecosystem Approaches to Health. In surveys at the end of the phase one work, community members had ranked water quality and garbage in the streets as high priority concerns. The goals of the UEHP project were to engage the community as co-researchers to develop a richer understanding of the interactions among the socio-cultural, politicaleconomic, and environmental determinants of human health, and to use this understanding to improve human health. Thus, while human health remained the ultimate goal, we had decided that this could best be achieved by improving the health of the eco-social system within which that health was one outcome (i.e., taking an ecosystem approach to health).

The broad overall goal was broken down into specific objectives: To assist communities in Wards 19 and 20 to define and describe the socioecological systems in which people live and work; to assist communities to identify indicators of ecosystem health; to assist communities to set short and long term goals related to the achievement of ecosystem health; to assist communities to implement feasible and desirable changes; and, to monitor and respond to the outcomes resulting from implementation of those changes.

The project encompassed a wide range of investigative methods, which reflected a consensus on our research team that methodological pluralism must be central to any new science for sustainability (Murray et al. 2002, Waltner-Toews et al. 2004). Conventional, quantitative scientific methods used included epidemiological surveys, water quality monitoring, and a variety of health assessments. These were complemented with more qualitative tools, drawn from Participatory Action Research (PAR), Freirian conscientization, and related fields such as participatory urban appraisal, gender analysis, semi-structured surveys, focus group discussions, appreciative inquiry, and stakeholder analysis.

Community Researchers (CRs), members of the local community, were hired and trained by the research team, and were facilitators for the focus groups. This was to ensure the development of local 
Fig. 1. The bank of the Bishnumati River adjacent to Wards 19 and 20, Kathmandu, 1992.

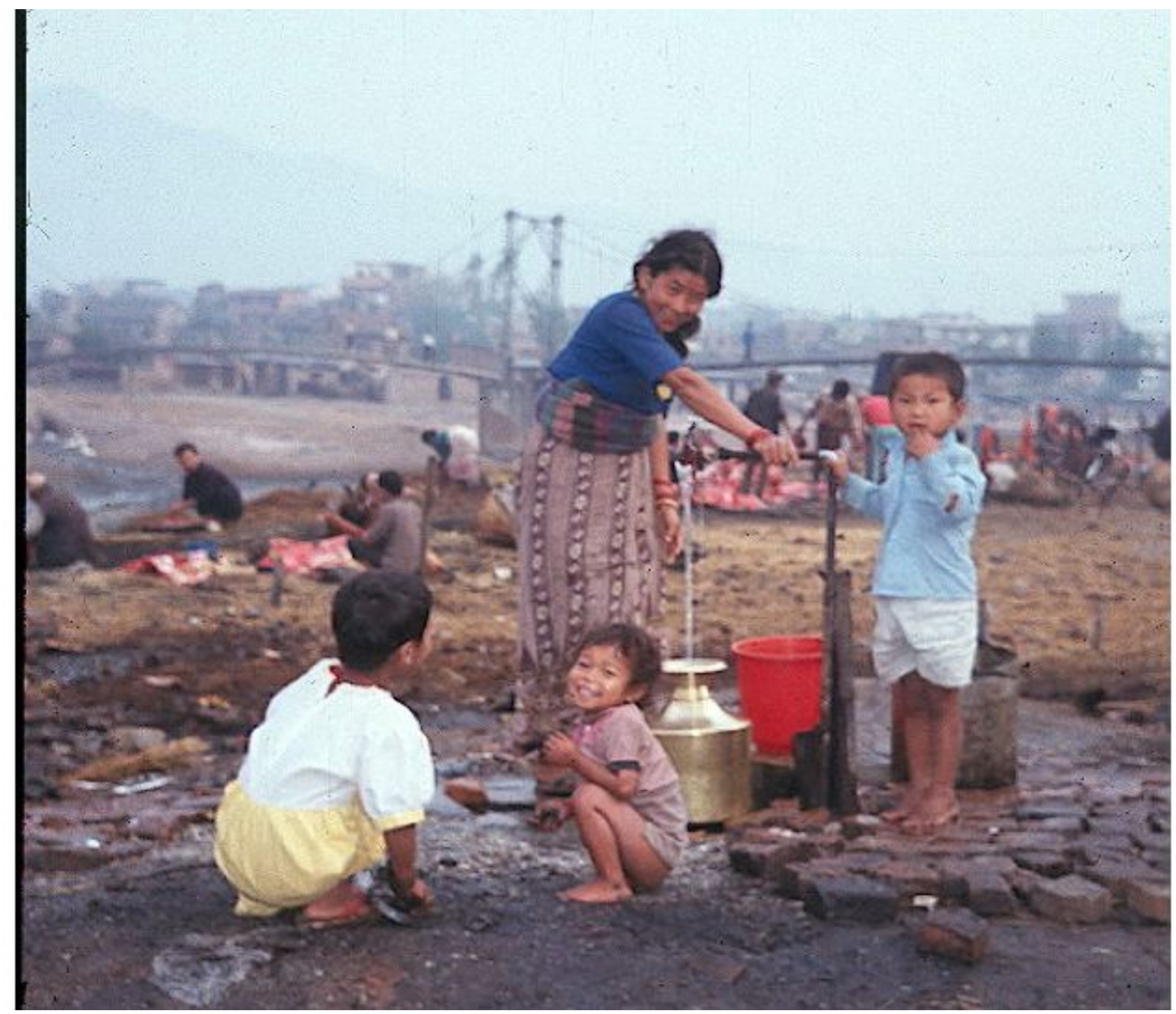

capacity for participatory action and research through the generation of awareness among local people. Initial community-wide workshops reaffirmed water quality and solid waste in the streets as priority concerns. Based on both PAR techniques and narratives, action plans were developed by various stakeholder groups in the community (butchers, street sweepers, permanent and street vendors, etc.), based on their own goals and priorities in relation to the larger aims of improving water quality and quantity, and garbage management. These plans were implemented to varying degrees.
As we neared the end of the project, however, there was a sense of un-ease among the researchers that the collective narrative of the community was not being adequately understood or addressed. The multiple perspectives and methods - effective as they were in addressing specific problems - left a sense of fragmentation. Indeed, it was becoming clear in the three projects (Nepal, Kenya, Peru) that research into sustainable health required not only that the scientific enterprise be embedded in processes of social engagement, but also that the social engagement and the science needed to take a holistic and systemic approach. 
Fig. 2. The bank of the Bishnumati River adjacent to Wards 19 and 20, Kathmandu, 1992.

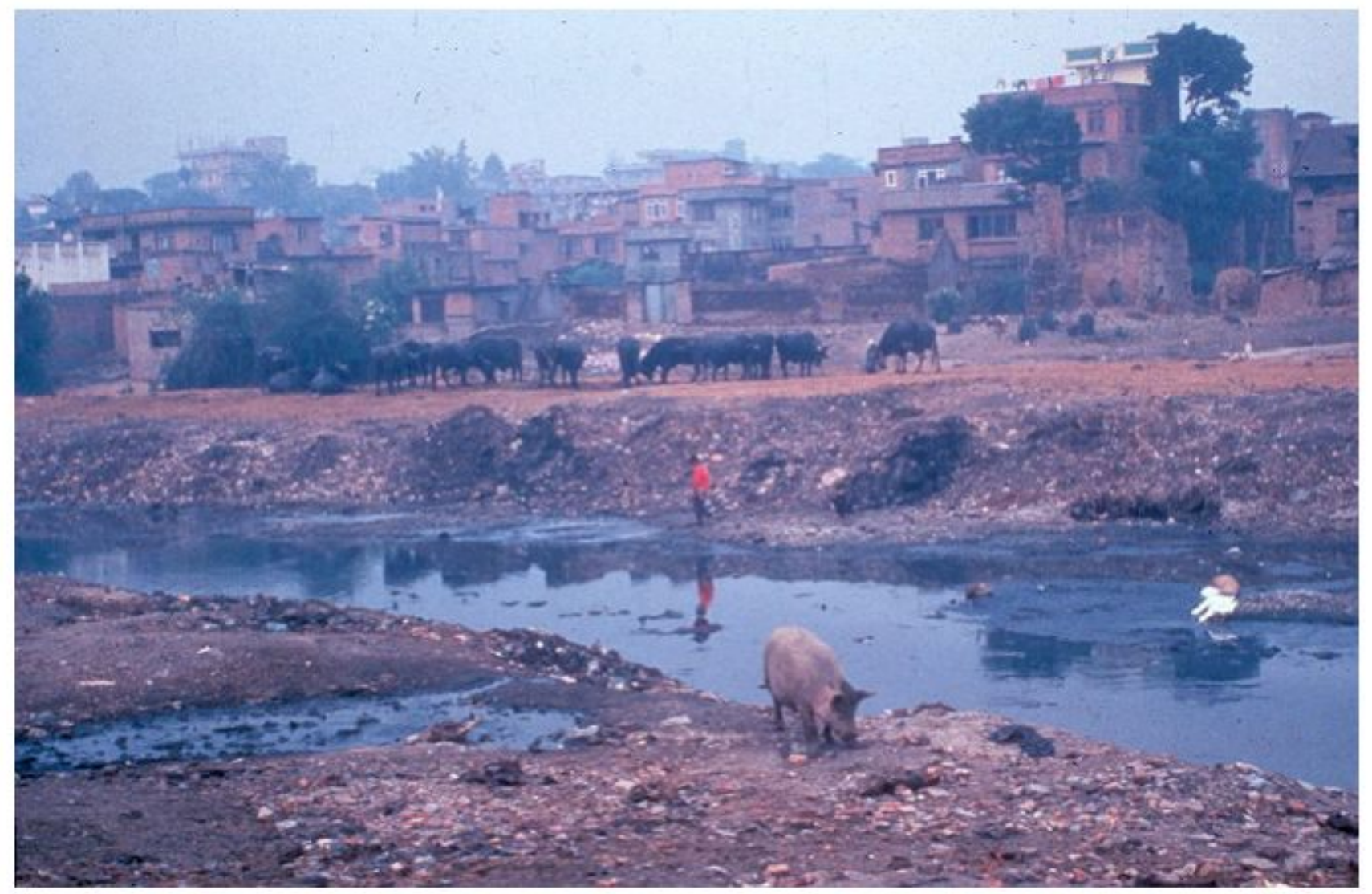

The full project and the research process used are discussed elsewhere (Waltner-Toews et al. 2005; Neudoerffer et al. in press). This paper has the more limited objective of highlighting one particular issue, multiple perspectives on a complex eco-social system, and one set of techniques, schematic diagrams, which we found useful for enabling both scholarly and community-based researchers to come to a better understanding of the complex context within which their issues of concern were embedded.

\section{CASE STUDY}

The UEHP was carried out in Wards 19 and 20, two urban wards in old Kathmandu. Kathmandu (elevation $1350 \mathrm{~m}$ ), the capital of Nepal, lies in the Bagmati and Bishnumati River Valley in the Kathmandu Valley, in the Hill Ecological Zone. Thirty years ago, Kathmandu was a small city and the valley was a patchwork of lush green fields and forested areas. After several decades of intense population growth, the Kathmandu District has grown at a rate of 4-6\% over 20 years, from 1981 (pop. 422 237) to 2001 (pop. 1081 845) (Central Bureau of Statistics 2005). Now the entire landscape 
of the valley bears the mark of human activity and transformation. In addition to agriculture, carpet industries and brick making dominate the economy. The annual precipitation in Kathmandu is very seasonal with more than $70 \%$ of the annual precipitation occurring during the four-month monsoon season (mid-June to mid-September). Given the topographic conditions, this translates into massive runoff during the rainy season and unless a river originates high in the mountain glaciers, there is little water available during the dry season (Schreier and Shah 1996). Kathmandu relies heavily on water from the Bagmati River system as a main source of drinking water. However, both the Bagmati and Bishnumati rivers are extremely polluted due to, among other sources, the dumping of industrial and municipal wastes, e.g. dyes and chemicals from the carpet-making industries and open sewers emptying into the rivers untreated.

The physical and political boundaries of Wards 19 and 20 circumscribed the primary study area. The Bishnumati River, bounding both wards to the west, is a strong physical boundary, a primary source of water for many residents, and a magnet for a wide range of activities. Historic Durbar Square marks the north-eastern boundary of the area. A dirt road separates the wards from the riverbank and, despite being in the heart of downtown Kathmandu, a number of community garden plots dot the riverbank and are found in the wards along with small livestock such as chickens and goats. In between the river, the community gardens, and the square is a densely packed mix of residential dwellings and commercial establishments. Several main streets, just wide enough for two small cars (or equally likely two rickshaws or bullock carts), wind uphill from the river to the main road leading to the square. Jutting off these main streets at odd angles are a warren of small lanes and footpaths. Houses are squeezed together cheek-by-jowl, stacked multiple additions to accommodate growing and extended families. Along the main streets and lanes, various stores: butcher shops, tailors, general dry goods stores, etc., occupy the bottom, street-level floor of many houses. Schools, health clinics, and the Municipal Ward offices are also found in the wards. The local residents span a broad socio-economic spectrum, from low caste street sweepers and squatters to high caste doctors and lawyers.

While many households count the Bishnumati River as their primary source of water, piped drinking water is available to a majority of residents in Ward 20 and a number of hand-pumps are also found in the area. A unique feature in the community is a fourth major source of water, dunge dharas or traditional stone water spouts. Dunge dharas are usually associated with a religious shrine or temple, the water runs continually, and many are several hundred years old. The location of the water source has been lost in history.

\section{METHODS}

Near the end of the project, the work was re-assessed using an Adaptive Methodology for Ecosystem Sustainability and Health (AMESH), which emerged from our experiences in Nepal, Peru, and Kenya, as well as related work by James Kay and his colleagues in Canada (Fig. 3) (Kay et al. 1999, Murray et al. 2002, Waltner-Toews et al. 2004, Waltner-Toews and Kay 2005). In brief, AMESH begins with a presenting situation, which is explored initially through secondary and historical data, and subsequently though workshops and surveys to identify stakeholders, issues and policy, and governance questions related to the same. Descriptive and explanatory narratives for how the current situation came to be are elicited from stakeholders; these, together with a variety of qualitative and quantitative investigative methods are used to explore causal structures from various perspectives and epistemologies, and to synthesize these into qualitative depictions that can be used by participants to identify connections and trade-offs, and to negotiate policies and actions. Outcomes are monitored and assessed, and the "loop" is closed as we alter our understanding of the system and the actions deemed feasible and desirable. The methodology contains elements of a wide variety of soft systems (Checkland and Scholes 1990), complex systems (Kay et al. 1999) and participatory methods (Pretty et al. 1995), which have emerged over the past half-century.

One of the key tenets of AMESH is that complex systems cannot, by definition, be understood using only a single perspective: both multiple perspectives and methodological pluralism are essential. Even within one general perspective, say western science, there is no a priori reason to privilege quantitative over qualitative results or mathematical modeling over heuristic diagramming. The methods used relate to the questions asked, the kinds of information required to answer those questions, and 
Fig. 3. The Adaptive Methodology for Ecosystem Sustainability and Health (AMESH).

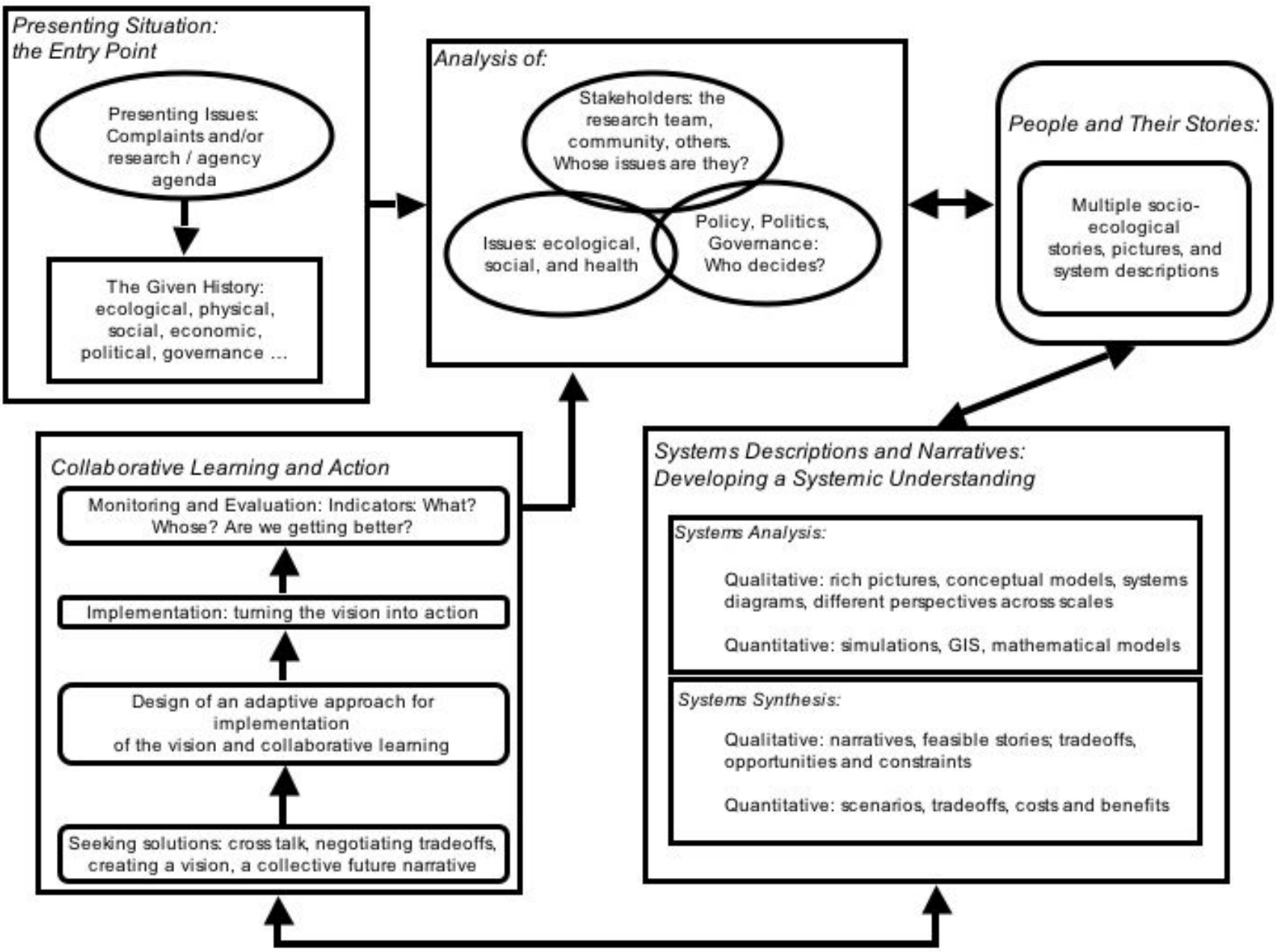

the feasibility of collecting that information in a manner appropriate to the goals and resources of the investigating team.

This paper specifically focuses on the component of the AMESH process termed "System Descriptions and Narratives: Developing a Systemic Understanding". Other steps in the process address issues of history and context (Step 1), governance and policy (Step 2), and collaborative action (Step 5); each of these is discussed in greater detail elsewhere (Waltner-Toews 2004, WaltnerToews et al. 2004; Neudoerffer et al. in press).
As noted in the introduction, this variant of the ecosystem health approach, one that seeks to develop a trans-disciplinary, integrative, and participatory action research approach to improving eco-social system health with an improvement in human health as one outcome of that system, is relatively new. Parkes and Panelli (2001) provide an excellent review of PAR, Public Health and Community Health Promotion, Natural Resources Management, Environmental Health, and Integrated Ecosystem-based Approaches to develop their COPAR or Community-Oriented Participatory Action Research approach to ecosystem health. Their framework includes four major steps: 
Initiations, Build Partnerships, Collaborative Initiatives, and Further Planner and Future Phases. A case study example is given in the Taieri River Catchment in the southeast of Otago in the South Island of New Zealand. Walker et al. (2002) have also developed a related framework for analyzing social-ecological resilience. Their framework also has four major steps: describing the system or asking resilience of what; developing visions and scenarios or asking resilience to what; analyzing resilience; and seeking stakeholder evaluation. Both of these frameworks have many similarities to AMESH, including defining the complex eco-social system of study, exploring goals and visions for the future to develop action plans; and considering how current institutional arrangements, including the distribution of power and wealth, influence decision-making. However, the Walker et al. framework is more consultatory than participatory in its inclusion of stakeholders. We believe that the fact that these three frameworks have each emerged separately, drawing on different case material, yet contain many similar elements, suggests that AMESH-type frameworks may be robust and have general applicability.

The intensive interaction among the research team, Community Researchers (CRs) and community members through focus groups, surveys, and PAR processes produced several hundred pages of narratives, one for each stakeholder group. These narratives describe how each stakeholder group perceives the interactions among themselves, other stakeholder groups, and the local ecosystem. Collectively, these stories provided a rich picture of the local ecosystem from a multiplicity of perspectives; however, they did not present a very clear overall picture of the web of interactions of the structures and processes that comprise the local eco-social system.

To translate these stakeholders' stories into a format more appropriate for identifying linkages and tradeoffs within a research team that had varying degrees of literacy in a variety of languages, we used a modified technique of influence analysis diagrams. Similar diagrammatic representations have been proposed and used by Checkland, Maruyama, Flood and Carson, and a variety of other authors, including our close colleague Thomas Gitau in Kenya, who died prematurely in 2005 and whose work has yet to be published (Checkland 1981, Flood and Carson 1993, Cayley and Sawada 1994, Gitau et al. 1998).
The diagrams map connections among a set of variables, where the interactions are complex and therefore not immediately obvious; we have found the method very useful in a variety of community, scholarly, and bureaucratic settings to untangle and chart complicated interconnections in some sort of manageable way. In Nepal, the diagrams were used to transform written narratives gathered through semi-structured interviews and focus groups into more structured diagrams that may be used for both formal and informal probing by community members and researchers. The goal was to highlight and make explicit linkages through a conceptual map that were difficult to see in a narrative form.

We began by examining the written narratives from the perspective of what they told us about the roles that local people played in their eco-social system and how their actions were affecting ecosystem health. The outcomes we used to characterize ecosystem health, based on the top priorities identified by the communities, were the state of the drinking water (primarily quality, but also quantity) and the status of solid waste management.

From our readings of the narratives, several themes began to emerge, which we developed into five categories of variables: stakeholders, activities, concerns, needs, and indicators of ecosystem health. A different set of researchers may have defined a different set of categories, based on their interests and perspectives. As researchers, our interests defined what issues we drew into the foreground of our analysis and what we chose to leave in the background. If we had started by asking a different question and thereby changed what we defined as 'foreground' versus 'background', we would have likely ended up with a different set of systems diagrams (Allen and Hoesktra 1992). This is a general problem of studying complex ecological, social, and eco-social systems of all sorts, and not peculiar to our work.

Nonetheless, throughout the research and analysis process the research team attempted to keep our own interests from interfering with 'hearing' the stakeholders issues and concerns. Triangulation (see Discussion) or the use of multiple methods, such as community meetings, focus groups, and semi-structured interviews, were used to elicit stakeholder perspectives, opinions, and ideas. The research team made concerted efforts to consider the stakeholders not as 'targeted beneficiaries' but rather as legitimate partners in the research process. 
One way of achieving this was through the use of CRs to do much of the in-the-field research. A total of 28 CRs were trained and part of our work. First four primary CRs (one male and one female from each Ward) were selected based on advice from the local community leaders, these were given training in Participatory Urban Appraisal (PUA) and Gender and Stakeholder Analysis (GSA). These four CRs then conducted a baseline PUA in the two Wards and identified 24 volunteers to serve as a Local Community Research Support Team. This extended research team, facilitated by the 'formal' research team conducted the field research. Finally, this research had the rare benefit of spanning 10 years. The original research project (phase one; see Historical Background) actually started out driven specifically by researchers' interests. As described in the Historical Background, after the first five years of phase one, a great deal of information had been collected and analyzed, but very little concrete change had taken place. The second phase, the UEHP, explicitly started with the recognition of the need for a different approach that was intentionally reflexive from the researchers' perspective and let the community concerns drive the research agenda.

We believe that this is one strength of genuinely participatory research; extensive participation by local community members, both as co-researchers and as active participants in research activities provides multiple opportunities for 'cross-talk' or discussion across perspectives. This cross-talk helps to ensure that multiple perspectives are 'heard' and acts as a check-and-balance, to ensure that one agenda, either the researchers' or another stakeholder's does not unduly dominate. We believe that this is one advantage of participatory over nonparticipatory research in this type of communitybased context. Despite this perceived advantage, however, participatory research is certainly not immune to 'capture' by one or more powerful interests. One way we attempted to minimize such 'capture' in our work was to explicitly identify ourselves, the researchers, as stakeholders in the project with our own interests and activities.

In this case study, the diagrams, based on written accounts from interviews and focus groups, were created by researchers and then presented back to the stakeholders at a later project workshop for verification. Ideally, such diagrams would be developed in the field, with the full participation of the local stakeholders as part of a series of focus groups (as Gitau did in Kenya). In the Nepal case, the diagrams were developed over several iterations within the Canadian research team; one researcher developing a draft and then gathering feedback from the research team. In a sense, such diagrams always remain works in progress; at a certain point, however, we accepted that they captured our best understanding of the available information and presented the work back to the stakeholders. If such diagrams can be 'kept alive' and an ongoing dialogue can be established with local stakeholders, they have the potential to become a powerful adaptive management tool used as a context to monitor and understand change within an AMESH type of process.

The general framework for our ecosystem health diagrams, which identifies a broad set of variables and their linkages (Anderies et al. 2004), is presented in Figure 4. The framework provides one possible representation of the elements contributing to ecosystem health; in a different context, other elements may be added to adequately capture the eco-social system of interest. Examples of the elements and their interactions are given in Tables 1 and 2.

Each active participant group is identified as a Stakeholder (A) in the eco-social system. A stakeholder may be an individual, a group, or a collection of groups. Activities (B) are actions that Stakeholders (A) take each day, or on a regular basis, that influence some aspect of ecosystem health either positively or negatively. Resource States (C), such as water quality, water quantity, or cleanliness of the street, are measurable indicators of ecosystem health. Stakeholders (A) express specific Needs (D), with respect to either their daily Activities (B) or Resource States (C). Stakeholders (A) also express more general Concerns (E), which may be related to one of their Activities (B), a particular Resource State (C), or may give rise to a more specific Need (D).

Using our framework, the first series of diagrams we developed were 'issues and influences' diagrams for each stakeholder group: butchers, sweepers, street vendors, hotel and restaurant owners, squatters, and community leaders. These diagrams attempted to capture the various stakeholders' interests around the two key ecosystem health themes identified through community meetings water quality and quantity, waste management and how their daily activities influenced or impacted upon local ecosystem health. Figures 5 and 6, the 
Fig. 4. Conceptual Model of Ecosystem Health.

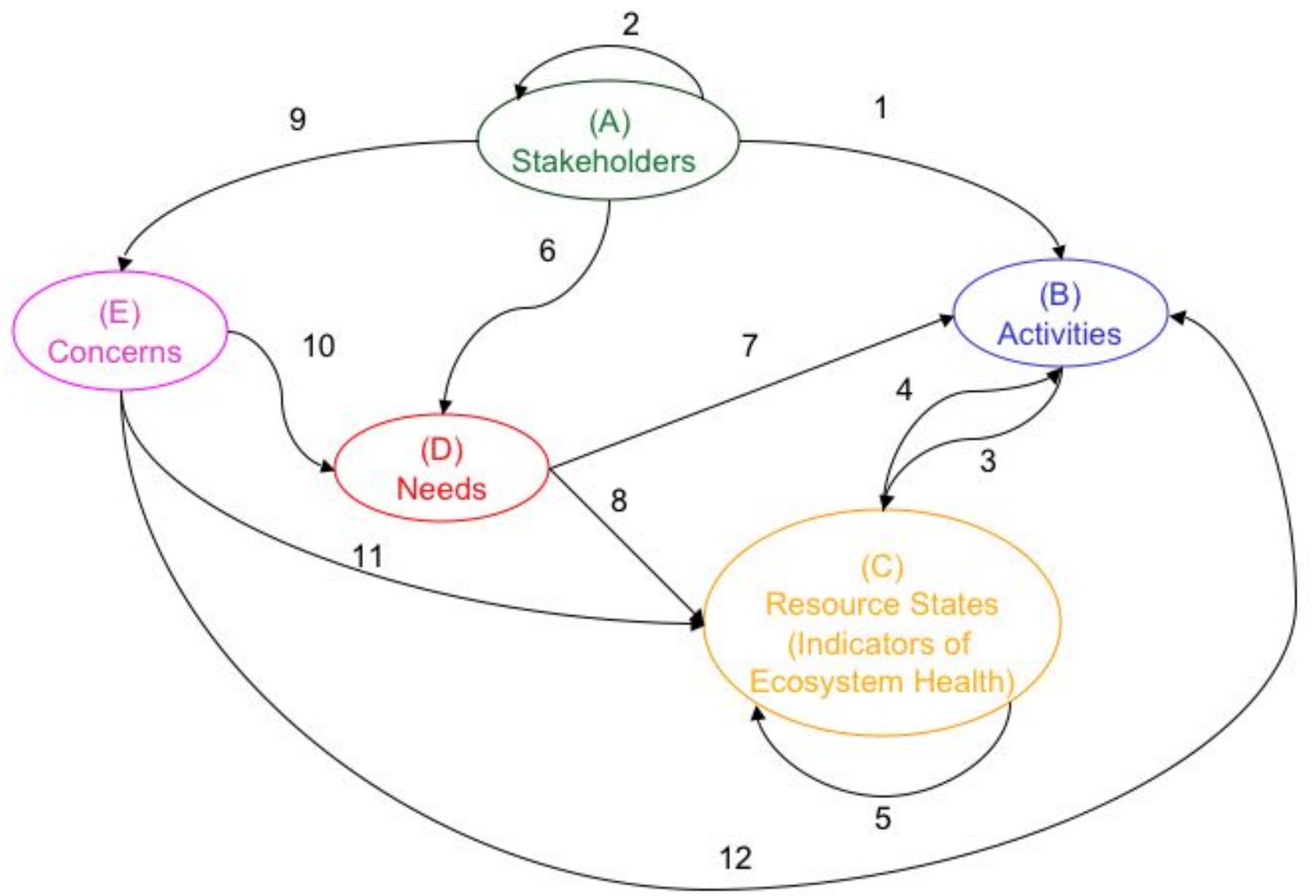

butchers and the sweepers diagrams, are presented here for discussion.

The stakeholder groups had been identified and named by the Nepali researcher partners. As Nepal is a Hindu country and a caste-based society, groups of people tend to disaggregate by caste and occupation. Even in participatory action research where a goal is collective action, the local realities needed to be recognized. In urban Kathmandu, this reality included the fact that low caste butchers and sweepers do not generally interact with high caste community leaders. Therefore, caste-based stakeholder groups naturally emerged.
General stakeholder groups could be further subdivided. For example, within the general 'butcher' group there were a number of specific stakeholders: the wholesalers or owners of the slaughter houses, the butchers (who are employees of the owners), the retailers or owners of the small meat shops who sold the meat to the public, the local customers who bought the meat, the Small Meat Market Association, an advocacy group formed by the slaughterhouse owners, and the local police (see Fig. 5). 
Table 1. Eco-social system elements contributing to ecosystem health.

\begin{tabular}{ll}
\hline \hline Element & Examples \\
\hline A. Stakeholders & Butchers, street sweepers. \\
B. Activities & Butchering meat, garbage management, sweeping streets. \\
C. Resource States & Cleanliness of the street, water quality, water quantity. \\
D. Needs & Garbage containers, Time to collect garbage. \\
E. Concerns & Not enough time to collect garbage. \\
\hline
\end{tabular}

The next step was to identify the daily activities of each stakeholder that influenced in some way the local drinking water or waste management system. The activities were described in the stakeholder narratives and provided a means to connect different stakeholders (i.e., stakeholders were connected via their activities or interactions on a daily basis). We started with the activities as each stakeholder group defined them (e.g., the first pass on the butcher's activities came from an analysis of how the butchers themselves defined their daily tasks in relation to ecosystem health outcomes). Details were added to the diagrams by including activities that other stakeholders described. For example, the butchers were said to engage in three main activities: garbage management, butchering, and 'yelling and throwing bones at the squatters' (Fig. 5). The butcher employees themselves said that their two key activities were garbage management and butchering. The squatter stakeholders suggested the third activity.

The third step was to pull out of the narratives the concerns each stakeholder expressed about any given activity. For example, the butchers felt intimidated by their employers and were not comfortable expressing their opinions in their presence, so the concern, 'feel intimidated by employers' was added to the issues and influence diagram. This is a good example of a concern that was not expressed directly, but rather emerged from interviews and discussions. The butcher employees did not directly state they were uncomfortable, rather their unwillingness to speak or express a contrary opinion in the presence of the owners or wholesalers confirmed the suspicion of the Nepali research partners.
The fourth step was to look at the needs that either arose out of each concern or were expressed separately. For example, the retailers or the owners of the small meat shops said they needed training, protective clothing, protective nets over the meat, and refrigerator storage to improve the quality of the meat sold in their shops. The female street sweepers were concerned about the health impacts of handling garbage and requested hygiene training and protective equipment (gloves, masks, and shoes).

The fifth step was to add how or whether the activities or needs affected or related to the state of the ecosystem health as measured by resource states. "Resource states", such as water quality and availability, served as our measures of ecosystem health. For instance, the butcher's impacts on ecosystem health were influenced by water availability (quantity of tap water and of tube well water) and water quality (tube well water). Water quantity limited what the butchers could do in terms of cleaning up; the large piles of refuse from slaughtering areas affected the quality of the water available for washing, and contaminants leached down into the often-fractured water system pipes.

The final step was to combine the five variable types (stakeholders, activities, concerns, needs, and resource states) into one comprehensive "issuesand-influences" diagram for each stakeholder group, such as those we show for butchers and for street sweepers (Figures 5 and 6). As all of the variables were combined into one diagram, the interconnections among variables were made.

For example, on the sweeper issues-and-influence diagram the need category of "garbage containers" 
Table 2. Links between eco-social system elements contributing to ecosystem health.

Link Examples

1. Between Stakeholders and Activities

2. Between two Stakeholders

\section{Between Activities and} Resource States

\section{Between Resource States and Activities}

\section{Between two Resource States}

6. Between a Stakeholder and a Need

7. Between a Need and an Activity

8. Between a Need and a Resource State

9. Between a Stakeholder and a Concern

10. Between a Concern and a Need

11. Between a Concern and a Resource State

12. Between a Concern and an Activity
Butchers slaughter and butcher meat every day

Street sweepers sweep the streets every day

An individual stakeholder may be a part of a group of Stakeholders, and this group in turn may be a part of a larger group, e.g., Wholesalers (or Slaughterhouse owners) are part of a Small Meat Marketing Association.

Garbage management (Activity) by the Butchers (Stakeholder) affects the Level of hygiene in the slaughterhouse (Resource State). Street sweeping (Activity) by Sweepers (Stakeholder) affects the Cleanliness of the Street (Resource State).

The Cleanliness of the street (Resource State) (e.g., type and amount of garbage) in turn also affects ability of Sweepers (Stakeholders) to Sweep the street (Activity).

Water availability (Resource State) affects the Level of meat shop hygiene (Resource State), e.g., if there is no water available, the shopkeeper cannot clean the shop and hygiene suffers.

Retailers (or meat shop owners; Stakeholders) need Garbage Containers, Training and Protective clothing (Needs).

The lack of Garbage Containers (Need) means that the Retailers (Stakeholders) end up Disposing of garbage in the street (Activity) for lack of another disposal option.

The Retailer's (Stakeholder lack of Training (Need) and Protective Clothing (Need) impacts on the Quality of meat sold (Resource State).

Street sweepers (Stakeholder) are concerned that they do Not have enough time to sweet the streets (Concern); this Concern may give rise to a Need (see Link 10).

Street sweepers (Stakeholders) are concerned that they do Not have enough time to sweep the streets (Concern) and they therefore Need time to collect garbage (Need).

Retailers (Stakeholders) do not perceive any local environmental problems (Concern), which indirectly influences the Quality of the meat sold (Resource State) and the Cleanliness of the streets (Resource State); if they see no problem, there is no need to change.

Street vendors (Stakeholder) expect street sweepers to clean the streets (Concern) and indirectly, therefore, have less incentive to see their Disposal of waste in the street (Activity) as an issue to be concerned about or in need of modification. was connected both to the resource state of "cleanliness of the street" and the street vendors' activity of "dispose vegetable waste in the street". The logic behind the connection is that the lack of garbage containers affects both the activity and the outcome of the activity. Not all of the connections were clear on our "first pass" and different variables were added as diagrams were revised through iterations of revisiting narratives and discussions among the researchers. The diagrams built on oneanother, as more stakeholders were included in the analysis different diagrams were created to improve our understanding of important relationships and identify relevant points of intervention.

\section{RESULTS}

Figure 5 illustrates the Issues-and-Influences diagram for the Butcher Stakeholder group. Three key stakeholders make up the stakeholder group: Wholesalers, Retailers, and Butchers. The main 
Fig. 5. Issues and influences - butcher stakeholders.

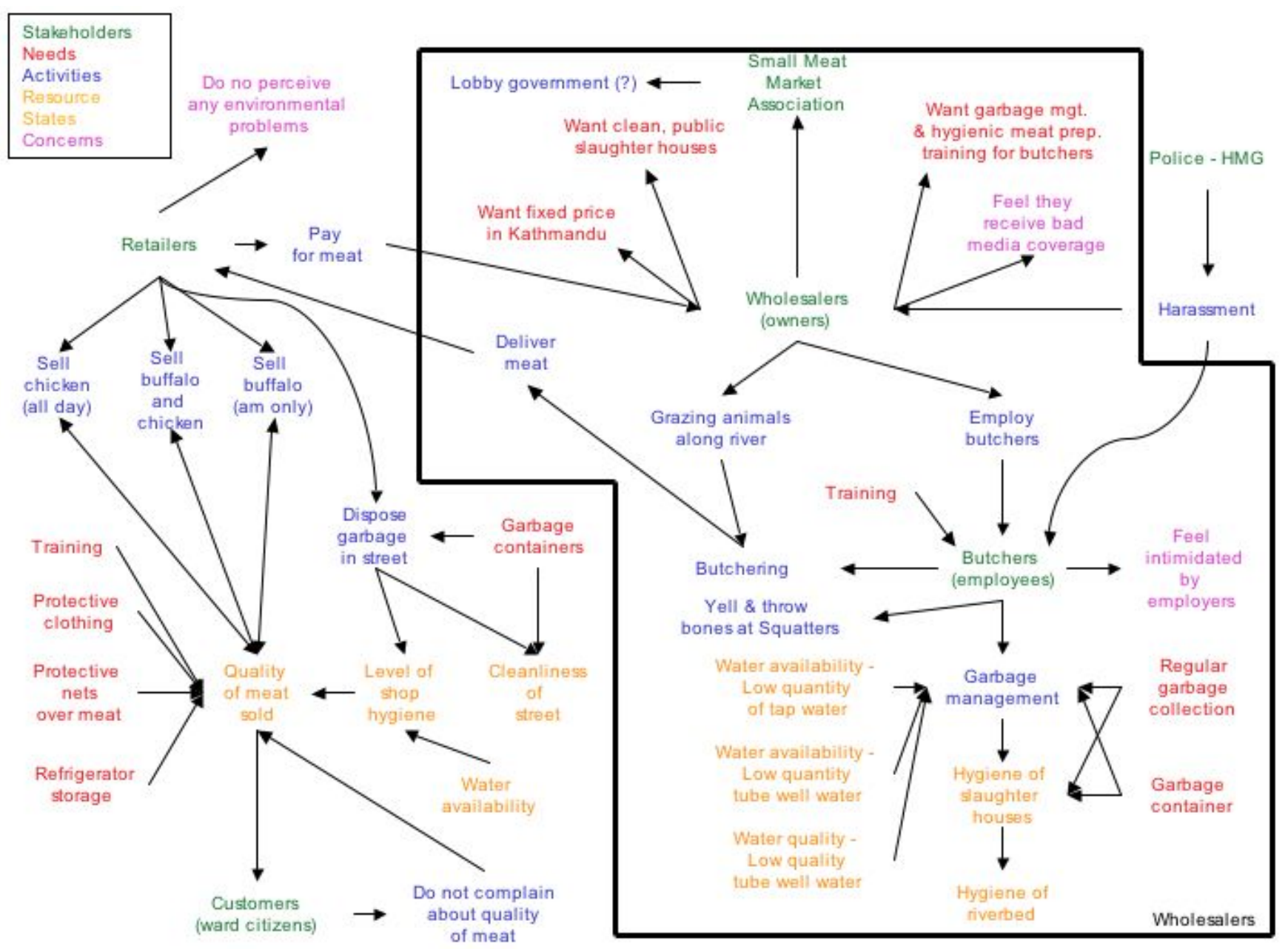

activities of stakeholders are butchering and selling meat; the ecosystem health outcomes of interest were hygiene of the slaughterhouse and riverbank, waste management, and water quality and quantity. The needs and concerns clearly varied by stakeholder perspective even within this group. For instance, the butcher employees were directly responsible for the generation of solid waste, which then influenced ecosystem health status measures related to slaughterhouse and riverbank hygiene. The butcher-employees' ability to do their jobs in this respect was influenced by the availability of water. They felt that if they were provided with better training, as well as garbage containers and more regular garbage collection, they would be able to do their jobs better. From their perspective, the police were there to harass them, and they (the butchers) had the unsavory task of driving away the squatters from the riverbank. The owners/ wholesalers who employed the butchers also thought their employees should get more training, but felt that at least part of the problem was one of bad media coverage. The owners/wholesalers are organized into a Small Meat Market Association, whose main role is to lobby the government. The local customers of the meat retailers were another 
Fig. 6. Issues and influences - sweeper stakeholders.

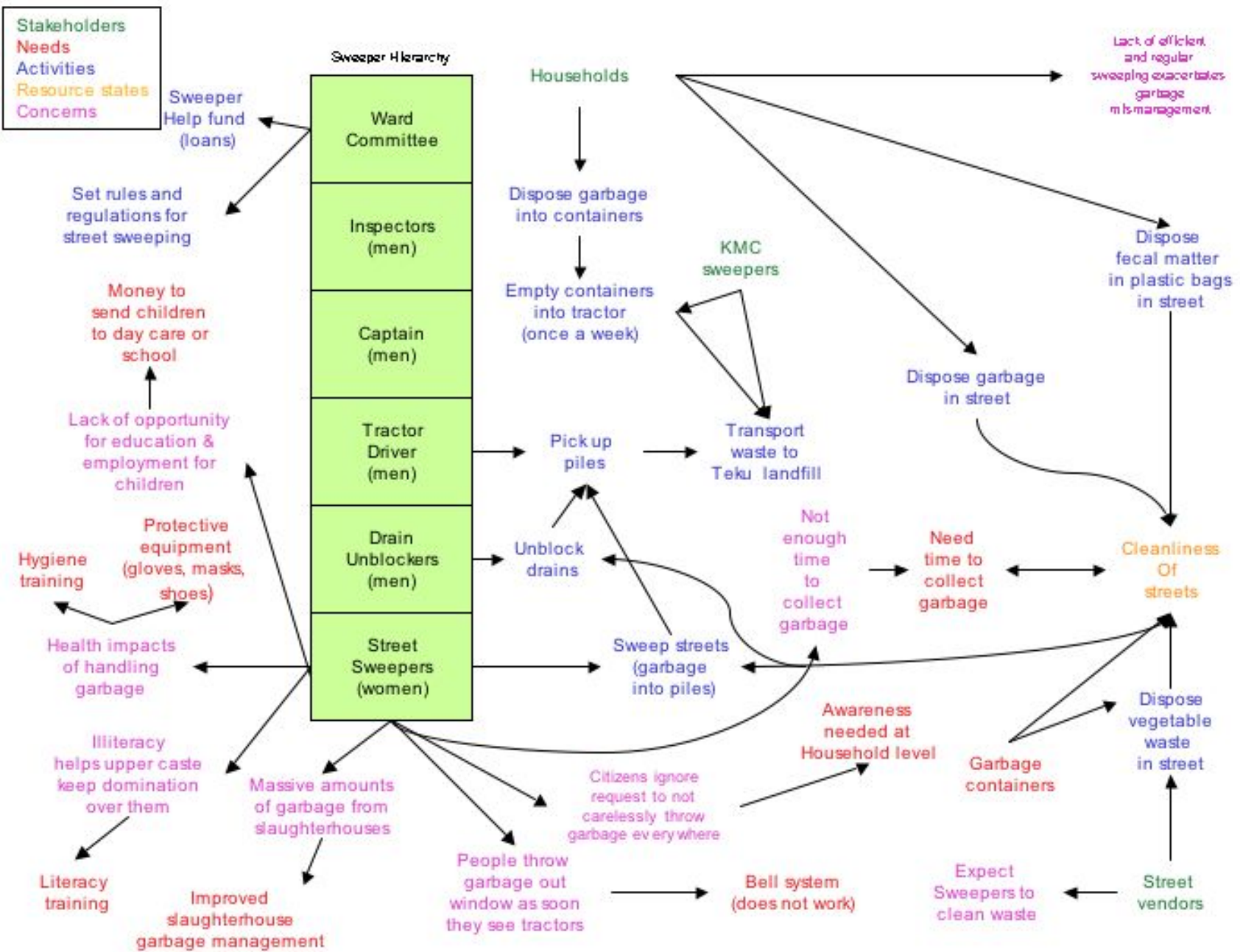

secondary yet important stakeholder that played a key role in driving the system (the customers do not complain about the quality of the meat sold). Hence, there seemed little incentive for other stakeholders to change practices.

Figure 6 illustrates the Issues-and-Influences diagram for the Sweeper Stakeholder group. Sweepers were not a homogeneous group, but were organized into a gender- and power-based hierarchy (stacked column of boxes, Figure 6). Political representatives on the ward committee were at the top of the hierarchy, hiring and employing all of the various street sweepers. Women, at the bottom of the hierarchy, did the actual work of sweeping the streets. In between were several employment roles held by men: inspectors, team captains, the driver of the tractors (which pulls the bins into which the street waste is collected), and 'drain unblockers' or men who pass along the streets ahead of the women and remove waste from the street drains. Activities are determined based on location in this hierarchy.

Figure 6 also captures needs and concerns expressed by the street sweepers. As with the butchers, it was clear that the people closest to the ground (that is, to actual garbage management) were those with the most concerns. Household heads (in the sweepers 
diagram), and retailers and wholesalers (in the butchers diagram) clearly thought the problem was someone else's. The (female) street sweepers not only argued for technical "fixes" related to improved garbage management, but also for improved educational opportunities for themselves and their children so that the upper classes could not so easily take advantage of them.

After drawing influence diagrams based on individual stakeholder groups, our next step was to look for different ways to synthesize the variables to attempt to gain a deeper understanding of the issues at hand from a more holistic 'systems' perspective. We started to think about different perspectives we could take on the data, or more technically, whether we could see different perspectives if a different set of variables were highlighted or brought to the foreground in the diagrams. Here we describe three different ways in which the ecosystem variables could be combined. These 'alternative perspectives' are akin to holding a prism up to the light and turning it, refracting the light through different facets and seeing different patterns and interplay of light. They are 'alternatives' in the sense that they are alternative ways of looking at the information found in the separate 'issues and influences' diagrams.

In the AMESH methodology, Systems Descriptions and Narratives: Developing a Systemic Understanding (Waltner-Toews et al. 2004) is divided into parts: system analysis and system synthesis. This overall step involves parsing and teasing apart different kinds of data (narratives, surveys, measurements, maps), and then putting them together in ways that would make sense of the overall system. Thus, in this case study, we took the varieties of data available, and created the 'issues and influence' diagrams, initially from different perspectives, but ultimately for the system overall. In Nepal, these diagrams were used primarily to reconstruct the information into a visual format, where interactions could be more clearly identified and discussed across language and cultural barriers. Because the type of data collected in this project was primarily qualitative in nature, the analysis was accordingly qualitative. The diagrams were used in discussions with multiple stakeholders to explore options and discuss 'what if' types of future scenarios. In some cases, if quantitative data are available and the research questions warrant such analysis, the diagrams can then be probed to 'analyze' the data; in Gitau's work in Kenya, he was able to create comprehensive diagrams together with the villagers, which were then amenable to dynamic systems and food-web analysis.

In Nepal, the stakeholder-based diagrams depicted the butchers concerns separately from the sweepers or street vendors and all of the potential actions (action plans) that had been devised on a stakeholder-by-stakeholder basis (i.e., one action plan for each stakeholder group with no common cohesive community plan). The synthesis diagrams were an attempt to bring these voices together in a way that had not yet been done.

Since the production and management of street waste were primary concerns in these communities, one important way to synthesize some of the information in the issues-and-influences diagrams was to bring together just the stakeholders and activities from all of the different 'issues-andinfluences' diagrams relating to these concerns. Figure 7 depicts how solid waste is generated in the community, and how it is cleaned up. This perspective is important in helping to create a cohesive understanding of how the activities of the various stakeholder groups combine and interact to give rise to a specific ecosystem health problem. The diagram illustrates that several stakeholder groups play an important role; highlighting the need to include, at a minimum, these groups in any effort to address street waste.

In a second system synthesis, we brought together all of the stakeholders and their concerns surrounding the food and waste system into one diagram (Figure 8). Thick arrows flag or highlight conflicting perspectives or concerns. The "Sweepers" had a different perspective regarding who was responsible for the street waste problem from the "Community Leaders" and the "Street Vendors". This diagram identified where stakeholders held divergent views and where there was a need to negotiate tradeoffs, future visions, and possible future actions. One of the obvious gulfs in perception was between the street sweepers and other members of the community. The sweepers saw the problem as being related to lack of time (labor shortages) and the behavior of householders and others in throwing their garbage into the street. Community leaders and vendors saw the problem as one of "laziness" ("sweepers shouldn't get weekends off") and bad management. The community leaders identified bad management as a problem but did not take responsibility for it; they saw management as a problem of the workers. In 
Fig. 7. Production and management of street waste.

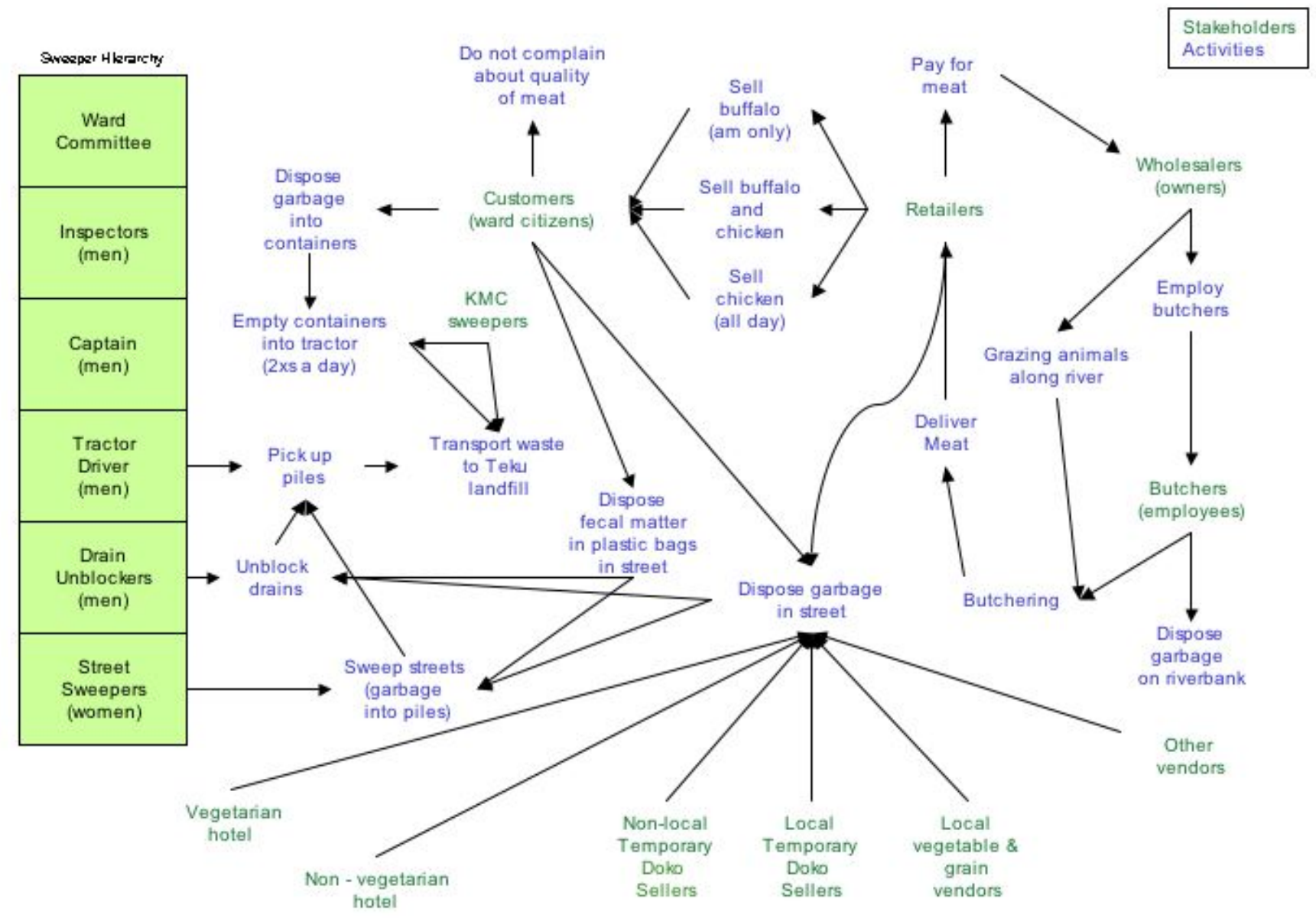

preparing this diagram, we also identified some gaps in our understanding related to stakeholder groups for which we had not collected or noted concerns regarding a particular issue (identified by the stakeholders pointing to the 'question-mark-?' concern in Figure 8).

It was not just important to consider how solid waste is generated and managed, but to elicit the interpretations and concerns of different stakeholders in relation to that. In order to identify concrete, feasible actions that would enable the communities to achieve their goals, it was also important to bring together, around the issue of food and waste, all of the stakeholders and needs (what would be needed to improve the situation) expressed relating to different resource states. The resource states were the agreed-upon indicators of the state of ecosystem health. In Figure 9, four different stakeholder groups, Street Vendors, Vegetarian and Nonvegetarian Hotel (restaurant) Owners, and Customers (ward citizens) all expressed the need for garbage containers. Garbage containers in turn affect the resource state, "Cleanliness of the streets". The Street Sweepers also expressed a number of needs, which also impact upon the same resource state. Hence, exploration, together with the stakeholders, of this type of system diagram, helped 
Fig. 8. Stakeholder concerns - food and waste system.

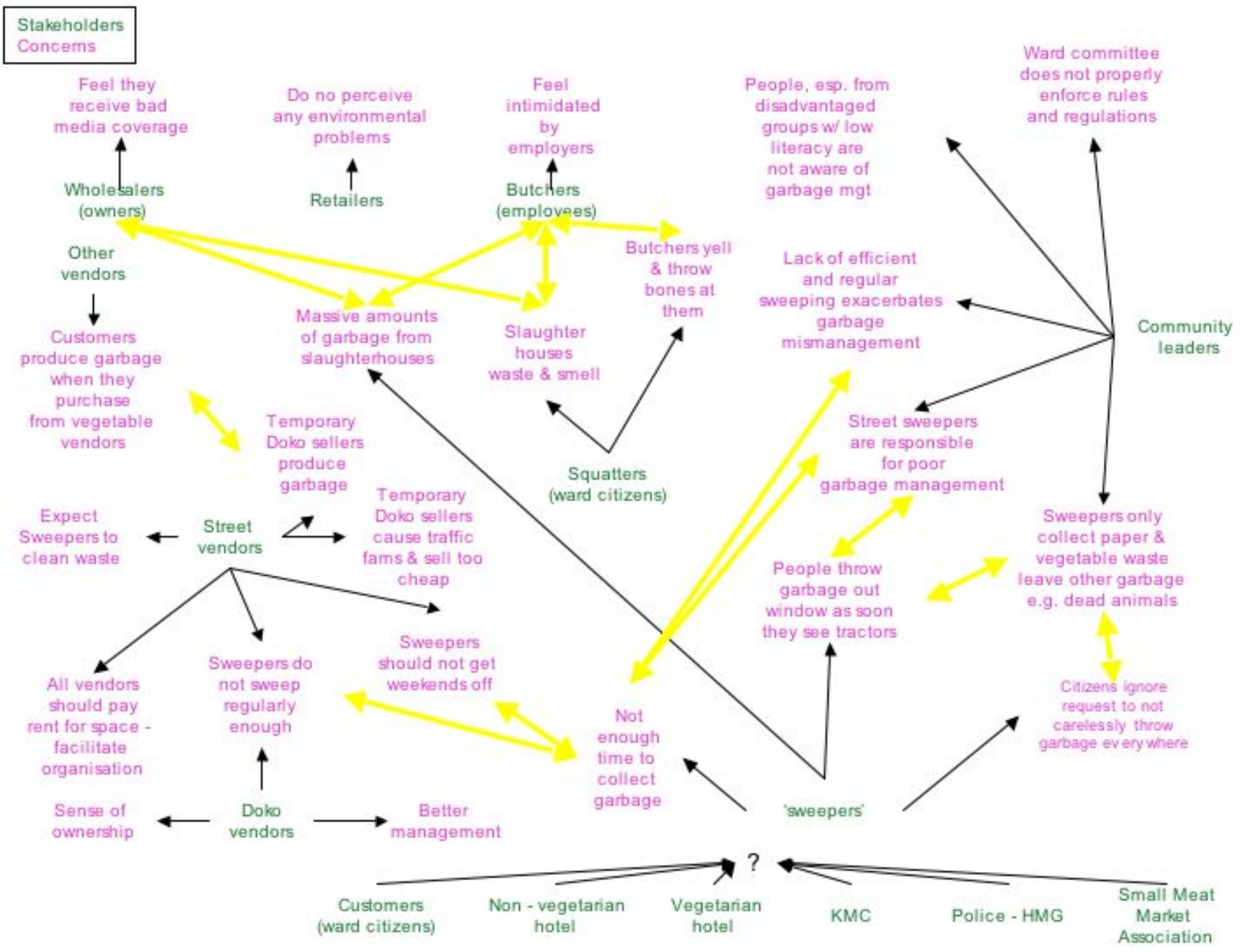

to identify stakeholders with common or complementary needs. This could then provide a basis for negotiating the collective goals and management practices (Stage 5 in AMESH) for improving their eco-social system.

\section{DISCUSSION}

Triangulation is a well-established method in a wide variety of disciplines for integrating information from different perspectives. In some disciplines, triangulation simply refers to using the same kind of information from different points in space to identify the position of a third element. In other disciplines, particularly in health care and environmental management, triangulation refers to bringing together information that has been gathered using a variety of methods from multiple perspectives. Physicians, veterinarians, and environmental managers do this all the time, drawing on laboratory results, empirical examinations, and qualitative histories to construct plausible explanations of current states. However, in most cases, the outcome of the triangulation is an informed "clinical judgment", with little formal guidance how one might arrive at such a desirable outcome (Waltner-Toews 2004). In many cases, 
Fig. 9. Stakeholder needs and resource states - water, food and waste

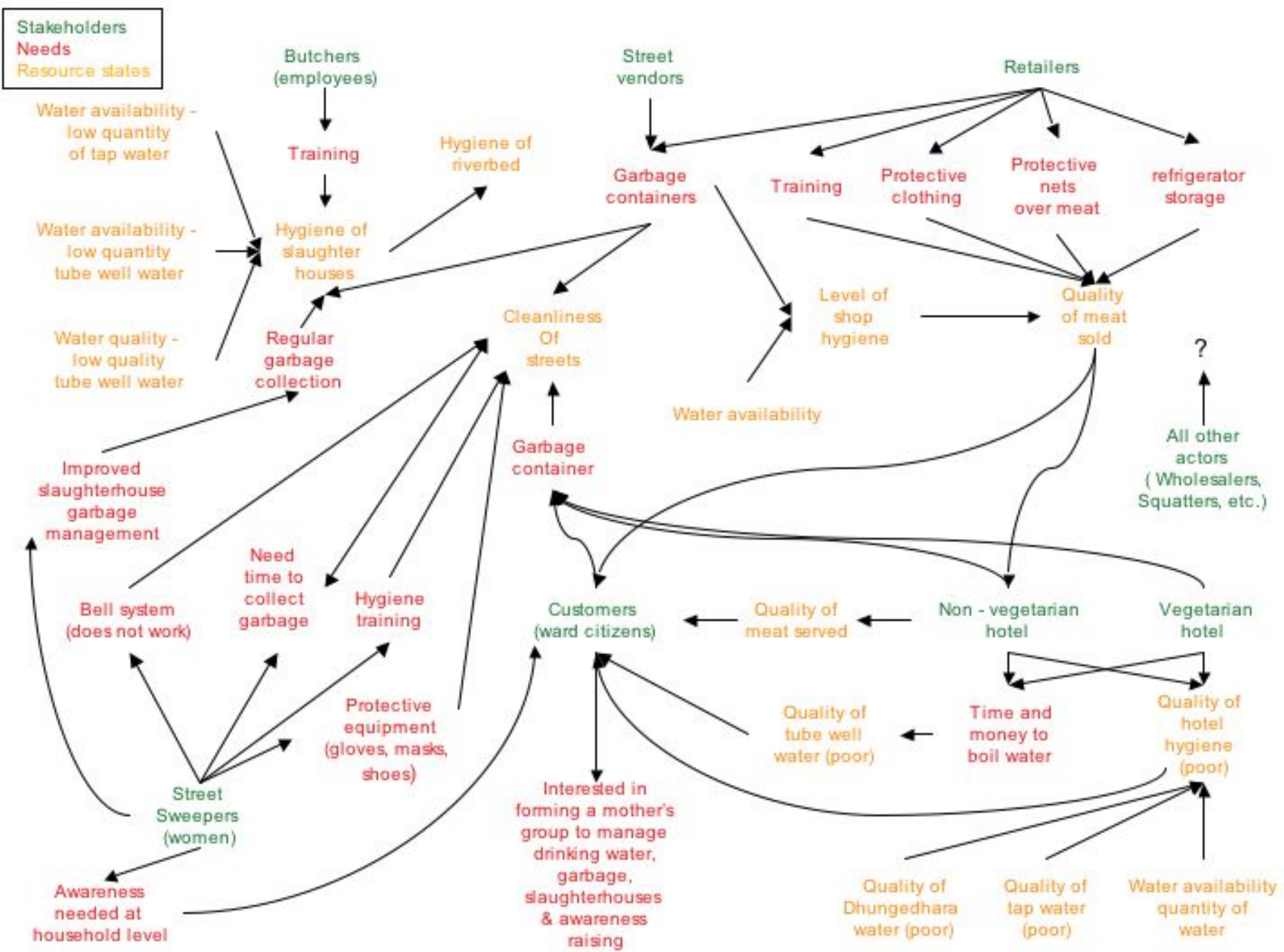

these judgments have been made intuitively by practitioners with long experience in a particular field.

A strong case for the use of triangulation with regard to decision-making for sustainability was put forward by Emery Roe (1998), and in the reviews and discussions which followed in Issue 4(2) of Conservation Ecology. However, one of the key issues that came to the fore in those discussions was that triangulation appeared to offer much in the way of analysis of complex problems but very little in the way of guidance for decision-making (see especially Raez-Luna 2000).
The techniques we used appeared to offer a way out of the traps sometimes created when too many kinds of information are brought together and the group that needs to act comes from very different backgrounds. While there are limits to such diagrammatic approaches, we found they enabled effective communication and stimulated discussion around appropriate courses of action to take. Our research team brought together a variety of stakeholder groups representing a variety of economic, political, and caste-based interests, including politicians, squatters, street sweepers, butchers, and local business owners. Thus, activities 
Fig. 10. The bank of the Bishnumati River adjacent to Wards 19 and 20, Kathmandu, 2001.

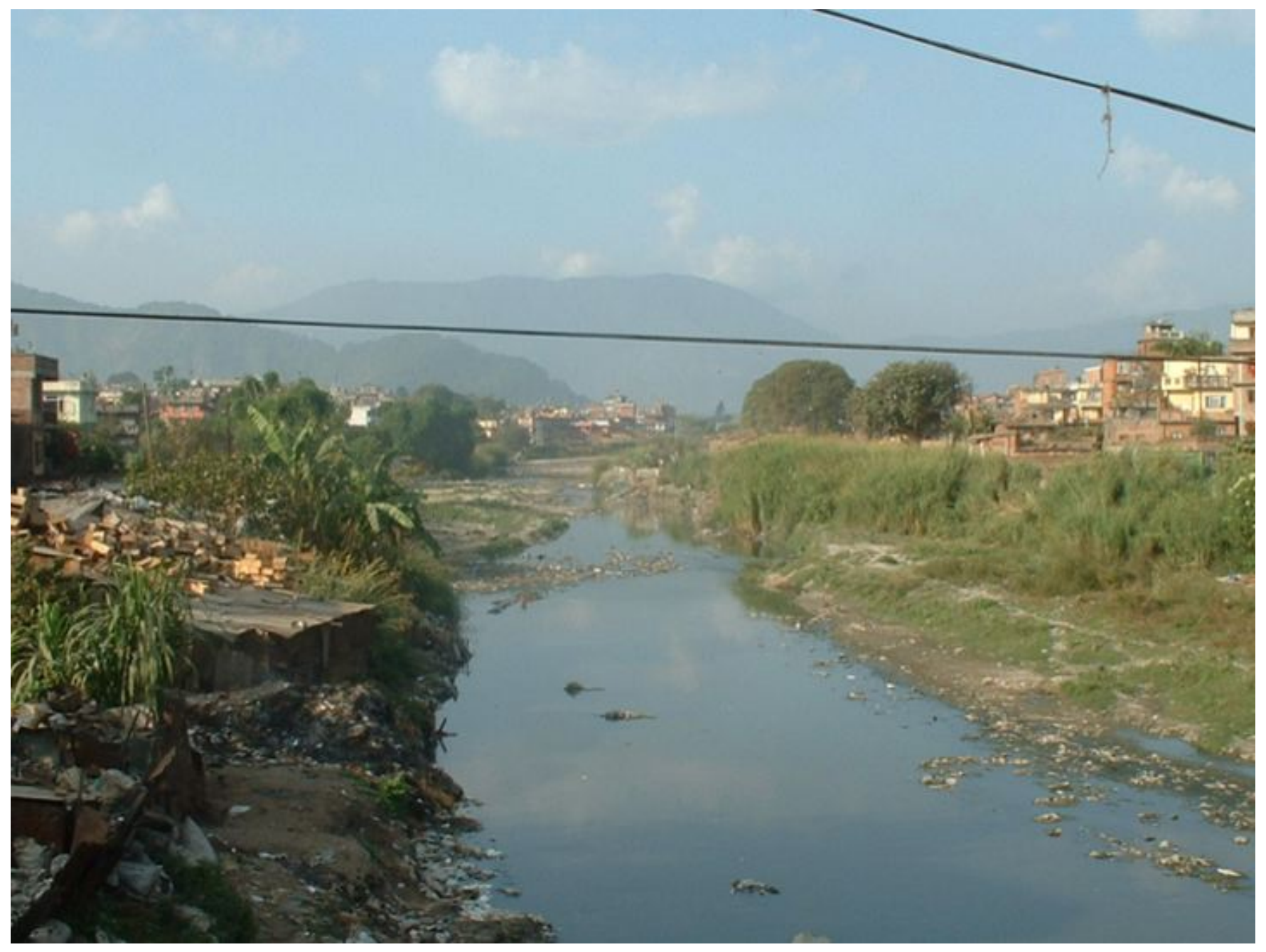

and initiatives of the local government, ineffective on their own, were complemented by volunteer clubs and private individuals who stepped in to facilitate recycling and composting programs, and religious groups that cleaned up some of the traditional water sources in the community. Indeed, by the last year of the UEHP, the communities had both physically and organizationally transformed themselves (that is, they had effectively triangulated the data and made decisions based on practical, rather than scholarly, considerations). Parks, gardens, and tall grasses were created along the riverbank, slaughtering areas were contained in courtyards away from the riverbank, slaughtering waste was composted, and water fountains were cleaned. Figures 10 and 11 illustrate the same area depicted in Figures 1 and 2, 10 years later. Perhaps more importantly, the butcher's association was taking initiatives in adult education, and local volunteer social clubs, working with small businesses and the local political authorities, were actively facilitating recycling and waste management programs. We were informed at one of our last meetings in 2001 that much of this occurred because the way the work had been structured fostered a sense of collective community in groups that had formerly been separated by caste and class. 
Fig. 11. The bank of the Bishnumati River adjacent to Wards 19 and 20, Kathmandu, 2001.

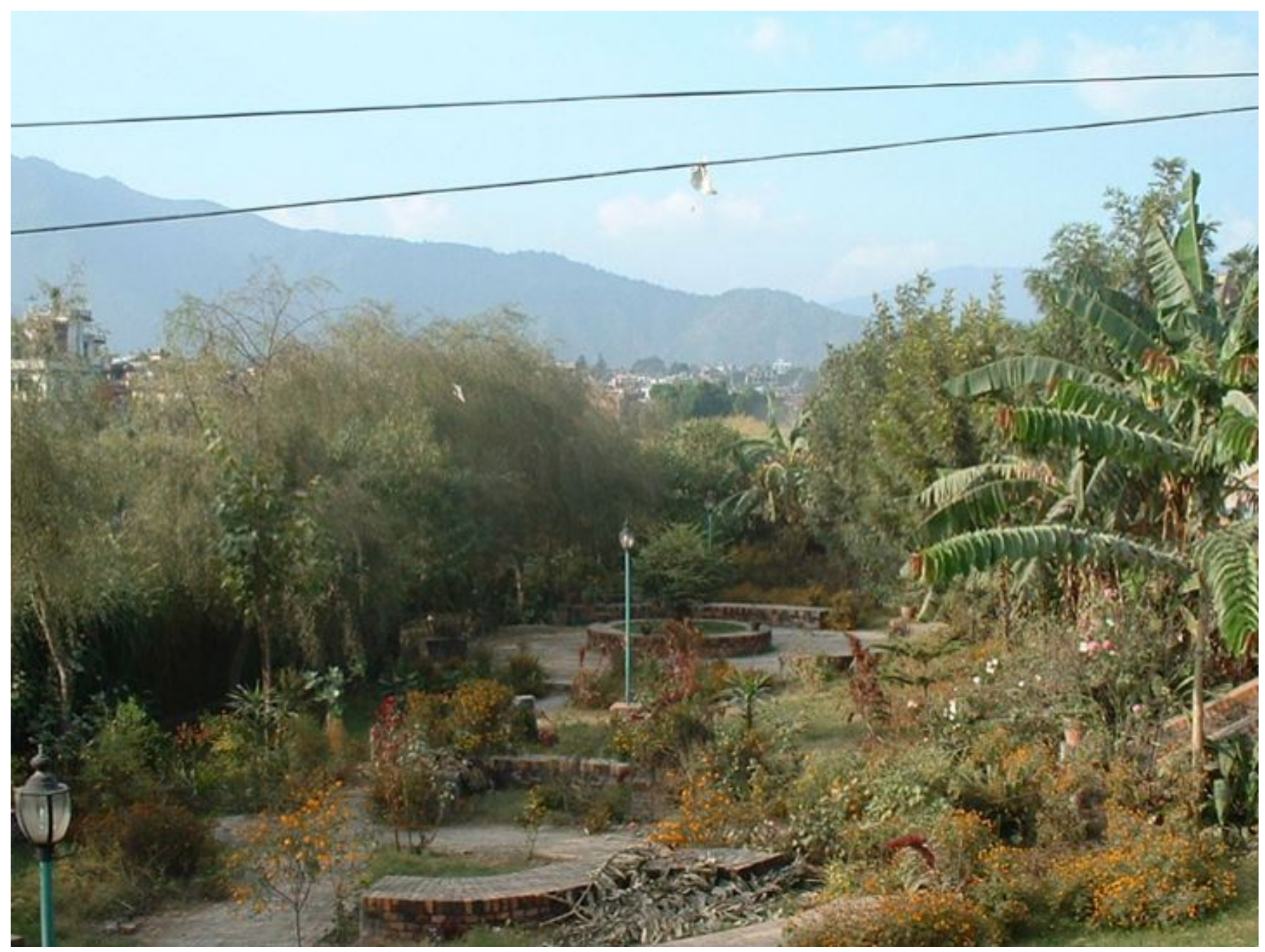

One might argue that such effective change is sufficient, regardless of whether or not it is based on scholarly understanding. However, unless we can more explicitly set out how the various perspectives relate to each other, we are unable to learn from the experience, identify gaps, and develop policies which can enable similar positive changes in the future and elsewhere.

Although many community activities identified as important in the systems diagrams had been undertaken based on more intuitive narratives, those narratives tended to close in on themselves and led to some fragmentation of understanding and action.
The use of influence diagrams helped clarify both the implications of what had been done and points of conflict, and suggested some appropriate strategies for moving forward. The diagrams also allowed for more transparent discussions among very different stakeholders. They transcended many language difficulties and bridged expert-lay cultures, since people were able to visualize relationships they had difficulty narrating. Gitau also found this in his work in Kenya.

The diagrams also enabled participants to identify constraints; for instance, as we discussed the collective diagrams we discovered that the Ward 
Committee does not have the authority to enforce local garbage management rules. This authority rests with the Municipality, so efforts need to be targeted at that scale, rather than merely locally, to be most effective. This had not emerged from the individual stakeholder narratives, but only when we diagrammed the system.

In an ideal case, such diagrams would be crafted in the field with the full participation of the local stakeholders over a series of discussions and focus groups. In this case, the 'layering' of the diagrams took place through multiple iterations with the research team. Although initiating the influence diagramming earlier in the project and collaboratively with local stakeholders, would have helped the communities to identify trade-offs and effective actions earlier, as was the case in the Kenyan Project (Gitau et al. 1998). Even late in the process, they provided a basis for the communities to learn from, build on, and move ahead.

At the final workshop of this project, both the individual stakeholder-perspective diagrams and our syntheses generated considerable discussion. In this, they helped all of us to achieve a richer understanding of the interactions among many of the socio-cultural and environmental variables in this urban ecosystem. As such, we believe that this work enriches and carries forward the notion of triangulation, and when used as a part of an adaptive research process such as AMESH, provides an important set of tools for integrating ecological and health variables, along with multiple stakeholder perspectives into the research process.

\section{CONCLUSIONS}

As the work of Kay et al. (1999), Parkes and Panelli (2001), Walker et al. (2002), and the work described here suggest, there appears to be a convergence of ideas as to how one might both investigate and manage complex, integrated, social, and ecological systems. Within these broad frameworks, a variety of well-established and newly adapted techniques are being put forward to facilitate work in various contexts to answer different questions. Our own work in Nepal, described here, has shown that influence diagrams can be usefully adapted from systems approaches, enabling better understanding, accommodation of multiple perspectives, and facilitation of strategic management action.
Responses to this article can be read online at:

http://www.ecologyandsociety.org/vollo/iss2/art12/responses/

\section{LITERATURE CITED}

Aguilar, B. J. 1999. Applications of Ecosystem Health for the Sustainability of Managed Systems in Costa Rica. Ecosystem Health 5(1):36-48.

Allen, T. and T. Hoekstra. 1992. Toward a unified ecology. Columbia University Press, New York, New York, USA.

Allen, T. H. F., B. Bandurski, and A. King. 1993. The ecosystem approach: theory and ecosystem integrity. Report to the Great Lakes Advisory Board. International Joint Commission, Ottawa, Canada, and Washington, D.C., USA.

Anderies, J. M., M. A. Janssen, and E. Ostrom. 2004. A Framework to Analyze the Robustness of Social-ecological Systems from an Institutional Perspective. Ecology and Society 9(1):18 [online] URL:

http://www.ecologyandsociety.org/vol9/iss1/art18

Baronet, D., D. Waltner-Toews, D. D. Joshi, and P. S. Craig. 1994. Echinococcus granulosus infection in dog populations in Kathmandu, Nepal. Annals of Tropical Medicine and Hygiene 88:485-492.

Berkes, F., and C. Folke, editors. 1998. Linking social and ecological systems. Cambridge University Press, Cambridge, UK.

Berkes, F., J. Colding, and C. Folke, editors. 2003. Navigating social-ecological systems: building resilience for complexity and change. Cambridge University Press, Cambridge, UK.

Callicott, J. B. 1995. A Review of Some Problems with the Concept of Ecosystem Health. Ecosystem Health 1(2): 101-112.

Casti, J. L. 1994. Complexification. HarperCollins, New York, New York, USA.

Caley, M. T., and D. Sawada, editors. 1994. Mindscapes: the epistemology of Magoroh Maruyama. Gordon and Breach, Amsterdam, 
Netherlands.

Central Bureau of Statistics. 2005. His Majesty's Government of Nepal, National Planning Commission Secretariat, Central Bureau of Statistics. [online] URL: http://www.cbs.gov.np/.

Checkland, P. B. 1981. Systems thinking, systems practice. John Wiley, Toronto, Ontario, Canada.

Checkland, P., and J. Scholes. 1990. Soft systems methodology in action. John Wiley, Toronto, Ontario, Canada.

CBD. 2005. Convention on Biological Diversity. [online] URL:

http://www.biodiv.org/programmes/cross-cutting/ ecosystem/default.asp.

Costanza, R. 1992. Toward an operational definition of health. Pages 239-256 in R. Costanza, B. Norton, B. Haskell, editors. Ecosystems health: new goals for environmental management. Island, Washington, D.C., USA.

Flood, R., and E. Carson. 1998. Dealing with complexity: an introduction to the theory and application of systems science. Plenum, New York, New York, USA.

Gaudet, C. L., M. P. Wong, A. Brady, and R. Kent. 1997. The Transition from Environmental Quality to Ecosystem Health. Ecosystem Health 3(1):3-10.

Gitau, T., J. McDermott, D. Waltner-Toews, and G. Otieno. 1998. Second Interim Report on an Integrated Assessment of Agricultural Communities in the Kenyan Highlands. These and other completed project reports can be accessed on the website of the Network for Ecosystem Sustainability and Health. [online] URL: http:// www.nesh.ca.

Gunderson, L., and C. S. Holling, editors. 2002. Panarchy: understanding transformations in human and natural systems. Island, Washington D.C., USA.

Hancock, T. 1990. Health, human development and the community ecosystem: three ecological models. Health Promotion International. 8(1):41-47.

Helmore, K., and N. Singh. 2001. Sustainable livelihoods: building on the wealth of the poor.
Kumarian, Bloomfield, Connecticut, USA.

Holling, C. S. 1986. The resilience of terrestrial ecosystems: local surprise and global change. Pages 292-317 in W.C. Clark and R.E. Munn, editors. Sustainable development of the biosphere. Cambridge University Press, Cambridge, UK.

Kay, J. J., H. Regier, M. Boyle, and G. Francis. 1999. An ecosystem approach to sustainability: addressing the challenge of complexity. Futures 31:721-742.

Lebel, Jean. 2003. Health: an Ecosystem Approach. International Development Research Center, Ottawa, Ontario, Canada. [online] URL: http:// www.idrc.ca/ecohealth.

Lee, K. 2001. The Global Dimensions of Cholera. Global Change \& Human Health 2(1):6-17.

Mageau, M. T., R. Costanza, and R. E. Ulanowicz. 1995. The Development and Initial Testing of a Quantitative Assessment of Ecosystem Health. Ecosystem Health 1(4):201-213.

McMichael, A. J., and R. S. Kovats. 2000. Global Environmental Changes and Health: Approaches to Assessing Risk. Ecosystem Health 6(1):59-66.

MEA. 2005. Millennium Ecosystem Assessment. [online] URL:

http://www.millenniumassessment.org/en/index.aspx

Murray, T., J. Kay, D. Waltner-Toews, and E. Raez-Luna. 2002. Linking Human and Ecosystem Health on the Amazon Frontier: an Adaptive Ecosystem Approach. Pages 297-308 in G. Tabor, M. Pearl, M. Reed, R. Ostfeld, A. Aguirre, J. Patz, and $\mathrm{C}$. House, editors. Conservation medicine: ecological health in practice. Oxford University Press, New York, New York, USA.

Neilsen, N. O. 1999. The Meaning of Health. Ecosystem Health 5(2):65-66.

Neudoerffer, R. C., D. Waltner-Toews, and J. J. Kay. In press. Return to Kathmandu: a Post-Hoc Application of AMESH. In D. Waltner-Toews, J.J. Kay, and N-M. Lister, editors. The Ecosystem Approach: complexity, uncertainty, and managing for sustainability. Columbia University Press, New York, New York, USA. 
Parkes, M., and R. Panelli. 2001. Integrating Catchment Ecosystems and Community Health: the Value of Participatory Action Research. Ecosystem Health 7(2):85-106.

Peden, D. 2002. Managing Agroecosystems for Better Human Health. Pages 4-8 in Ecosystem Disruptions and Human Health. Summary report of a consultation hosted by Canada's International Development Research Center (IDRC) and the United Nations Environment Programme (UNEP), November 14-17,1999, as part of the Canadian Conference on International Health, Hull, Quebec. Special supplement to LEISA magazine. Leusden, Netherlands.

Pretty, J., I. Guijt, I. Scoones, and J. Thompson. 1995. A trainer's guide for participatory learning and action. International Institute for Environment and Development, London, UK.

Price-Smith, A. T. 2002. The Health of Nations: infectious diseases, environmental change, and their effects on national security and development. MIT Press, Cambridge, Massachusetts, USA.

Ráez-Luna, E. 2000. Complex issues: complex methods? Conservation Ecology 4(2):9. [online] URL: http://www.consecol.org/vol4/iss2/art9/.

Rapport, D. 1995. Ecosystem Health: Exploring the Territory. Ecosystem Health 1(1):5-13.

Rapport, D., R. Costanza, P. R. Epstein, C. Gaudet, and R. Levins, editors. 1998. Ecosystem health. Blackwell Science, Malden, Massachusetts, USA.

Roe, E. 1998. Taking complexity seriously: policy analysis, triangulation and sustainable development. Kluwer Academic, Boston, Massachusetts, USA.

Schreier, H., and P. B. Shah. 1996. Water dynamics and population pressure in the Nepalese Himalayas. GeoJournal 40(1-2):45-51.

Spiegel, J. M., M. Bonet, A. Yassi, E. Molina, M. Concepcion, and P. Mas. 2001. Developing Ecosystem Health Indicators in Centro Habana: a Community-based Approach. Ecosystem Health 7 (1):15-26.

US FWS. 2005. U.S. Fish and Wildlife Service [online] URL: http://www.fws.gov/ecosystems/.

VanLeeuwen, J. A., D. Waltner-Toews, T. Abernathy, and B. Smit. 1999. Evolving Models of Human Health Toward an Ecosystem Context. Ecosystem Health 5(3):204-219.

Walker, B., S. Carpenter, J. Anderies, N. Abel, G. S. Cumming, M. Janssen, L. Lebel, J. Norberg, G.D.Peterson, and R. Pritchard. 2002. Resilience management in social-ecological systems: a working hypothesis for a participatory approach. Conservation Ecology 6(1): 14. [online] URL: http://www.consecol.org/vol6/iss 1/art14.

Waltner-Toews, D. 2004. Ecosystem sustainability and health: a practical approach. Cambridge University Press, Cambridge, UK.

Waltner-Toews, D., and J. J. Kay. 2002. An Ecosystem Approach to Health. Pages 15-16 in Ecosystem Disruptions and Human Health. Summary report of a consultation hosted by Canada's International Development Research Center (IDRC) and the United Nations Environment Programme (UNEP), November 14-17,1999, as part of the Canadian Conference on International Health, Hull, Quebec. Special supplement to LEISA magazine. Leusden, Netherlands.

Waltner-Toews, D., J. Kay, C. Neudoerffer, and T. Gitau. 2003. Perspective changes everything: managing ecosystems from the inside out. Frontiers in Ecology and the Environment 1(1):23-25.

Waltner-Toews D., J. J. Kay, T. Murray, and R. C. Neudoerffer. 2004. Adaptive Methodology for Ecosystem Sustainability and Health (AMESH): an Introduction. Pages 317-349 in G. Midgley, and A. E. Ochoa-Arias, editors. Community operational research: systems thinking for community development. Plenum/Kluwer, New York, New York, USA.

Waltner-Toews, D., C. Neudoerffer, D. D. Joshi, and M. S. Tamang. 2005. Agro-urban ecosystem health assessment in Kathmandu, Nepal: epidemiology, systems, narratives. Ecohealth 2:1-11.

Waltner-Toews, D., and J. Kay. 2005. The Evolution of an Ecosystem Approach: the Diamond Schematic and an Adaptive Methodology for Ecosystem Sustainability and Health. Ecology and Society 10(1):38. [online] URL:

http://www.ecologyandsociety.org/vol10/iss1/art38/ 
Watson, R. T., and A. J. McMichael. 2001. Global climate change - the latest assessment: does global warming warrant a health warning? Global Change \& Human Health 2(1):64-75.

Wilcox, B. A. 2001. Ecosystem Health in Practice: Emerging Areas of Application in Environment and Human Health. Ecosystem Health 7(4):317-325.

WHO. 1948. WHO Constitution Basic Text. [online] URL:

http://policy.who.int/cgi-bin/om isapi.dll?hitsperheading= on\&infobase $=$ basicdoc\&jump $=$ Constitution \&softpage $=$ Document42\#JUMPDEST Constitution.

WHO. 1978. WHO Alma Ata Declaration. [online] URL: http://www.euro.who.int/AboutWHO/ Policy/20010827_1

WHO. 1986. Ottawa Charter for Health Promotion. A declaration of the First International Conference on Health Promotion, Ottawa, Canada, November 17-21, 1986, published by the WHO Regional Office for Europe. [online] URL: http://www.euro. who.int/AboutWHO/Policy/20010827_2

Yassi, A., P. Mas, M. Bonet, R. B. Tate, N. Fernandez, J. Spiegel, and M. Perez. 1999. Applying an Ecosystem Approach to the Determinants of Health in Centro Habana. Ecosystem Health 5(1):3-19. 